\title{
Defect Chemistry, Surface Structures, and Lithium Insertion in Anatase $\mathrm{TiO}_{2}$
}

\author{
Carol L. Olson ${ }^{\dagger}$ and Jenny Nelson* \\ Department of Physics, Blackett Laboratory, Imperial College London, Prince Consort Road, \\ London SW7 2BW, United Kingdom
}

\author{
M. Saiful Islam \\ Department of Chemistry, University of Bath, Bath, BA2 7AY, United Kingdom
}

Received: December 12, 2005; In Final Form: March 11, 2006

\begin{abstract}
Atomistic simulation techniques are used to investigate the defect properties of anatase $\mathrm{TiO}_{2}$ and $\mathrm{Li}_{x} \mathrm{TiO}_{2}$ both in the bulk and at the surfaces. Interatomic potential parameters are derived that reproduce the lattice constants of anatase, and the energies of bulk defects and surface structures are calculated. Reduction of anatase involving interstitial $\mathrm{Ti}$ is found to be the most favorable defect reaction in the bulk, with a lower energy than either Frenkel or Schottky reactions. The binding energies of selected defect clusters are also presented: for the $\mathrm{Ti}^{3+}-\mathrm{Li}^{+}$defect cluster, the binding energy is found to be approximately $0.5 \mathrm{eV}$, suggesting that intercalated $\mathrm{Li}$ ions stabilize conduction band electrons. The $\mathrm{Li}$ ion migration path is found to run between octahedral sites, with an activation energy of $0.45-0.65 \mathrm{eV}$ for mole fractions of lithium in $\mathrm{Li}_{x} \mathrm{TiO}_{2}$ of $x \leq$ 0.1 . The calculated surface energies are used to predict the crystal morphology, which is found to be a truncated bipyramid in which only the (101) and (001) surfaces are expressed, in accord with the available microscopy data. Calculations of defect energies at the (101) surface suggest that single $\mathrm{Ti}^{3+}$ defects and neutral $\mathrm{Ti}^{3+}-$ $\mathrm{Li}^{+}$pairs tend to segregate to the surface.
\end{abstract}

\section{Introduction}

Titanium dioxide $\left(\mathrm{TiO}_{2}\right)$ is a technologically important material with applications in photocatalysis, paints, gas sensors, electrochromic devices, lithium ion batteries, and dye-sensitized solar cells. $\mathrm{TiO}_{2}$ crystallizes most commonly in either the rutile (space group $P 4_{2} / \mathrm{mmm}$ ) or the anatase (space group $I_{1} / a m d$ ) phase. For bulk $\mathrm{TiO}_{2}$ crystals at ambient conditions, rutile is more stable than anatase ${ }^{1}$ and has therefore been more widely studied. Anatase is the more stable phase for crystals of nanometer dimensions ${ }^{2}$ and is now becoming a technologically important material because of the facile synthesis of nanocrystalline $\mathrm{TiO}_{2}$ and its applications in areas such as dye-sensitized solar cells (DSSCs) ${ }^{3}$ and photocatalysis. ${ }^{4}$ Anatase $\mathrm{TiO}_{2}$ differs from the rutile form in that it has a lower dielectric constant and is less dense, thereby allowing lithium intercalation more readily. ${ }^{5}$

In a dye-sensitized solar cell, the nanocrystalline anatase electrode is composed of a porous network of particles of $\sim 15$ $\mathrm{nm}$ in diameter, which have been sintered together to ensure electronic contact. The electrode is sensitized with a light absorbing dye and placed in contact with a redox active electrolyte, such that photoexcitation of the dye leads to electron injection into the $\mathrm{TiO}_{2}$ and hole collection by the electrolyte. The efficiency and rate of electron transport though the nanocrystalline anatase electrode to the external circuit are important factors controlling the performance of the device. In particular, electron transport is believed to control the rate of interfacial charge recombination, which is the main loss

\footnotetext{
* Correspondng author. Tel: +44 20 75947581; e-mail: jenny.nelson@ imperial.ac.uk.

Current address: Energy Research Centre of the Netherlands, 1755 ZG Petten, The Netherlands.
}

mechanism. ${ }^{6,7}$ A wide range of experimental evidence indicates that the charge transport is controlled by electron trapping (reviewed in ref 8), yet the nature of the trapping sites has not yet been established. Candidates are nonstoichiometric or defect species such as $\mathrm{Ti}^{3+}$, interstitial $\mathrm{Ti}^{4+}$, and interstitial $\mathrm{Li}^{+}$, as well as surface adsorbed species. Therefore, it is of considerable practical interest to investigate the defect chemistry of anatase $\mathrm{TiO}_{2}$ to determine which defect reactions are energetically favorable, as well as to estimate the binding energies associated with possible defect clusters. Another relevant question is the preferential location of the trap sites within the film, with various reports concluding that electron traps are located predominantly at the surface of the nanoparticles, ${ }^{9,10}$ at the grain boundaries, ${ }^{11}$ or uniformly though the bulk of the particles. ${ }^{12}$ A recent study ${ }^{10}$ provides strong evidence that the traps are located predominantly at the nanoparticle surface, and it is therefore of interest to address this conclusion via simulation.

The role of lithium ions in the DSSC is of particular interest. Lithium is added to the electrolyte to improve device performance, and it has been shown that the amount of lithium in the electrolyte controls the electron injection yield from the dye into $\mathrm{TiO}_{2}{ }^{13-15}$ and the rate of interfacial charge recombination. ${ }^{16}$ Lithium also increases the conductivity of the $\mathrm{TiO}_{2}$ electrodes. ${ }^{17,18}$ The electrochemical insertion of $\mathrm{Li}^{+}$ions into $\mathrm{TiO}_{2}$ can be described by the equation

$$
x \mathrm{Li}^{+}+\mathrm{TiO}_{2}+x \mathrm{e}^{-} \leftrightarrow \mathrm{Li}_{x} \mathrm{TiO}_{2}
$$

where $x$ is the mole fraction of $\mathrm{Li}$ in $\mathrm{TiO}_{2}$. As lithium ions enter the $\mathrm{TiO}_{2}$ lattice, they cause electrons to enter the conduction band of $\mathrm{TiO}_{2}$, to compensate for the positive charge of the $\mathrm{Li}^{+}$ ions. ${ }^{19}$ At least some of these electrons reduce $\mathrm{Ti}^{4+}$ ions to $\mathrm{Ti}^{3+} .20$ The location and electrostatic effect of the $\mathrm{Ti}^{3+}$ and $\mathrm{Li}^{+}$ species are important in determining the potential distribution 
in the nanoparticles ${ }^{18}$ and are also important for applications in lithium ion batteries and electrochromic devices.

The use of computer simulation to investigate defect structures, transport energetics, and surface structures at the atomic level, in systems that may be difficult to investigate by experimental techniques alone, is now well-established. Atomistic simulation has been applied successfully to a range of functional oxides and lithium battery materials including rutile $\mathrm{TiO}_{2},{ }^{21} \mathrm{LiMn}_{2} \mathrm{O}_{4},{ }^{22,23} \mathrm{LiFePO}_{4},{ }^{24} \mathrm{SnO}_{2},{ }^{25}$ and $\mathrm{CeO}_{2}-\mathrm{ZrO}_{2} \cdot{ }^{26}$

The aim of this work is to use atomistic simulation techniques to study the defect chemistry and mechanism of lithium migration in anatase $\mathrm{TiO}_{2}$, with a particular focus on the regime relevant to DSSCs. In this paper, we first derive potential parameters for anatase $\mathrm{TiO}_{2}$ that reproduce the observed structure. Using these parameters, we calculate defect energies in the bulk to determine the most favorable bulk defect types. We show that $\mathrm{Li}^{+}-\mathrm{Ti}^{3+}$ defect clusters are energetically favorable, and we find the path and activation energy of lithium ion migration. We calculate the surface energies to determine the most energetically stable surface structures and predict the equilibrium crystal morphology. Finally, we examine the energies of $\mathrm{Ti}^{3+}$ and $\mathrm{Li}^{+}$defect ions as a function of distance from the surface to investigate any tendency for these ions to segregate toward or away from the surface.

\section{Atomistic Simulation Methods}

Computational techniques for atomistic simulation of ionic materials are well-established and will only briefly be explained here since comprehensive reviews are available elsewhere. ${ }^{27}$

The simulations are based upon the Born model of the polar solid, with the short-range interatomic forces represented by effective pair potentials. It is important to note that while ions are considered to have integral charges, the electron distribution does not necessarily correspond to a fully ionic system, and the general validity of the model comes from its ability to reproduce the observed properties of a material. The Buckingham potential, $\phi_{i j}$, given in eq 2 , is used to treat the short-range interactions

$$
\Phi_{i j}=A \exp \left(-\frac{r_{i j}}{\rho}\right)-\frac{C}{r_{i j}{ }^{6}}
$$

where $r_{i j}$ is the separation of the ion centers, and $A, \rho$, and $C$ are ion-ion parameters. The shell model, in which each ion is represented as a massless shell connected to a core by a harmonic spring, is used to take electronic polarization of ions into account. This approach has been successful in modeling dielectric and elastic properties of many ionic solids. Lattice energy calculations are combined with energy minimization methods so that structural parameters are adjusted to obtain a minimum energy configuration. These methods (as implemented in the GULP $^{28}$ computer code) are used throughout this work.

In calculating energies associated with defects in the lattice, a key aspect is to allow the lattice to relax around the defect center. The Mott-Littleton approach ${ }^{27,29}$ was used, in which the crystal lattice is divided into two regions: the immediate vicinity around the defect (region 1) and the rest of the solid (region 2). In region 1, where the effect of the defect is strong, each atom is treated explicitly and allowed full relaxation, while the rest of the crystal is treated by quasi-continuum methods. With reliable interatomic potentials and a sufficiently large defect region, these simulation methods give accurate values of lattice polarization and Coulomb energies.
The oxide surface was modeled using techniques similar to those used to model the bulk. Whereas the bulk structure and properties were calculated assuming an infinite three-dimensional crystal lattice, the crystal surface is considered as a stack of planes periodic in two dimensions, with the ions near the surface allowed to relax from their ideal lattice positions. The computer code METADISE (Minimum Energy Techniques Applied to Dislocation Interface and Surface Energies), which has been applied to surface structures of other oxides, ${ }^{30,31}$ was used to simulate the surfaces of $\mathrm{TiO}_{2}$ and $\mathrm{Li}_{x} \mathrm{TiO}_{2}$. In this method, the structure and energy of a surface are obtained by relaxing the ions to their mechanical equilibrium positions. This is achieved via a two region approach in which the ion coordinates in the surface region are adjusted so that they experience zero net force, while those ions that are distant from the surface are kept fixed at their bulk equilibrium positions. The sizes of the surface regions were chosen to be large enough to ensure that the surface energy had converged.

The surface energy per unit area, $\gamma_{l}$, of a particular surface is calculated from the difference between the energy of the surface block, $E_{\text {surf }}$, and the energy of the same number of bulk ions, $E_{\text {bulk, }}$ per unit area, thus

$$
\gamma_{i}=\frac{E_{\text {surf }}-E_{\text {bulk }}}{\text { area }}
$$

The crystal morphology was predicted from the surface energies using a method ${ }^{31}$ based on Wulff's theorem, ${ }^{32}$ itself based on the proposal, due to Gibbs, that the total surface energy, $\gamma$, for a given volume should be minimized at equilibrium

$$
\gamma=\sum_{i} \gamma_{i} A_{i}=\text { minimum for constant volume }
$$

where $\gamma_{i}$ and $A_{i}$ are the surface energy and the surface area of the $i$ th crystallographic face, respectively. This approach is only valid for crystals grown with all faces in equilibrium and does not take into account kinetic factors such as growth rate, but it does allow for relaxation of the surface and is well-suited to exploring nanoscale crystallites. ${ }^{33}$ Mackrodt and co-workers ${ }^{34}$ have shown that this surface relaxation is an essential prerequisite in the prediction of correct morphologies for other oxide systems, namely, $\alpha-\mathrm{Al}_{2} \mathrm{O}_{3}$ and $\alpha-\mathrm{Fe}_{2} \mathrm{O}_{3}$. Similar methods have been used to explore the crystal morphologies of other inorganic solids such as calcites, ${ }^{35}$ zeolites, ${ }^{36}$ and perovskite oxides, ${ }^{37}$ where the calculated morphologies agree well with observation.

\section{Results and Discussion}

Structural Modeling. The interatomic potential and shell model parameters used in this work to model anatase $\mathrm{TiO}_{2}$ are listed in Table 1. The lattice parameters and dielectric constants of anatase calculated using these parameters are listed in Table 2. The calculated lattice parameters are within $3 \%$ of the experimental values. The calculated dielectric constants in the $a b$ plane $\left(\epsilon_{\perp}\right)$ and parallel to the $c$ axis $\left(\epsilon_{\|}\right)$of 7.3 and 8.4, respectively, are at the lower end of the range of experimentally determined values ${ }^{38-41}$ but are not unreasonable given the scatter in the experimental values. The experimental values for rutile are significantly higher than for anatase, with $\epsilon_{\|}$exceeding $\epsilon_{\perp}$ $\left(\epsilon_{\|}=173, \epsilon_{\perp}=89^{42}\right)$. These higher values suggest that interactions between defects are likely to be shorter-ranged in rutile than in anatase because of screening effects.

A range of parameter sets from previous studies of $\mathrm{TiO}_{2}$ (in most cases rutile $)^{43-46}$ was also applied to the anatase structure. However, none of these reproduced both the anatase structure 
TABLE 1: Interatomic Potential and Shell Model Parameters Used in This Paper

$\begin{array}{lcc}A(\mathrm{eV}) & \text { Buckingham }(\mathrm{Ti}-\mathrm{O}) & \\ \rho(\AA) & & 511.7 \\ C\left(\mathrm{eV} \AA^{6}\right) & & 0.2625 \\ & & 0 \\ A(\mathrm{eV}) & \text { Buckingham }(\mathrm{O}-\mathrm{O}) & \\ \rho(\AA) & & 12420.5 \\ C\left(\mathrm{eV} \AA^{6}\right) & & 0.2215 \\ & & 29.07 \\ k_{\mathrm{O}} & \text { Spring Constant }\left(\mathrm{eV}^{-2}\right) \\ k_{\mathrm{Ti}} & & 31 \\ & & 314 \\ \mathrm{O} & \text { Shell Charge (e) } & \\ \mathrm{Ti} & & -2.8 \\ & & -0.1\end{array}$

TABLE 2: Experimental and Calculated Lattice Parameters and Dielectric Constants of Anatase

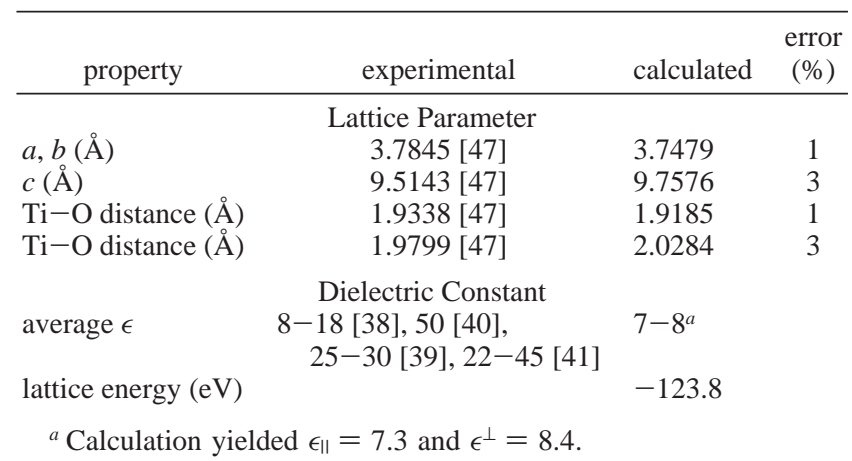

TABLE 3: Energies for Creation of Isolated Point Defects in Anatase

\begin{tabular}{lllr}
\hline \multicolumn{1}{c}{ defect } & symbol & \multicolumn{1}{c}{$\begin{array}{c}\text { position } \\
\text { (fract coord) }\end{array}$} & $\begin{array}{c}\text { energy } \\
(\mathrm{eV})\end{array}$ \\
\hline titanium vacancy & $\mathrm{V}_{\mathrm{Ti}^{\prime}{ }^{\prime \prime \prime \prime}}$ & $(0.000,0.000,0.000)$ & 95.30 \\
oxygen vacancy & $\mathrm{V}_{\mathrm{O}}{ }^{\circ *}$ & $(0.000,0.000,0.208)$ & 24.10 \\
titanium (4+) interstitial & $\mathrm{Ti}_{\mathrm{i}}{ }^{\circ \cdots}$ & $(0.490,0.010,0.250)$ & -77.23 \\
titanium (3+) interstitial & $\mathrm{Ti}_{\mathrm{i}}{ }^{\circ *}$ & $(0.000,0.500,0.700)$ & -40.51 \\
oxygen interstitial & $\mathrm{O}_{\mathrm{i}}{ }^{\prime \prime}$ & $(0.002,0.200,0.460)$ & -13.80 \\
lithium interstitial & $\mathrm{Li}_{\mathrm{i}}{ }^{\circ}$ & $(0.990,0.990,0.510)$ & -7.46
\end{tabular}

${ }^{a}$ With reference to infinity.

and the dielectric constants simultaneously but resulted in either large deviations in the lattice parameters or negative dielectric constants. The potentials developed in this work were refined from previous potentials of Grimes ${ }^{44}$ using successive NewtonRaphson iterations, with the goal of finding a parameter set that yields values of both the structural parameters and the dielectric constants that are in the range of experimental values, while including electronic polarization in the model. We stress that this has not been a trivial task. Ion polarizability is essential to the accurate calculation of energies of charged defects since distortion of electron clouds is an important local relaxation mechanism.

Bulk Defects. The energies for the creation of various isolated point defects, namely, titanium and oxygen vacancies and titanium, lithium, and oxygen interstitials, were calculated using the potentials given in Table 1 and are presented in Table 3. For example, to calculate the energy of a vacancy, an ion has to be removed from the lattice and placed at an infinite distance. Also given in Table 3 is the position of the lowest energy interstitial site for each species, which was found by placing the corresponding ion at various positions in the unit cell and allowing the structure to relax. The $\mathrm{Ti}^{4+}$ and $\mathrm{Li}^{+}$interstitials

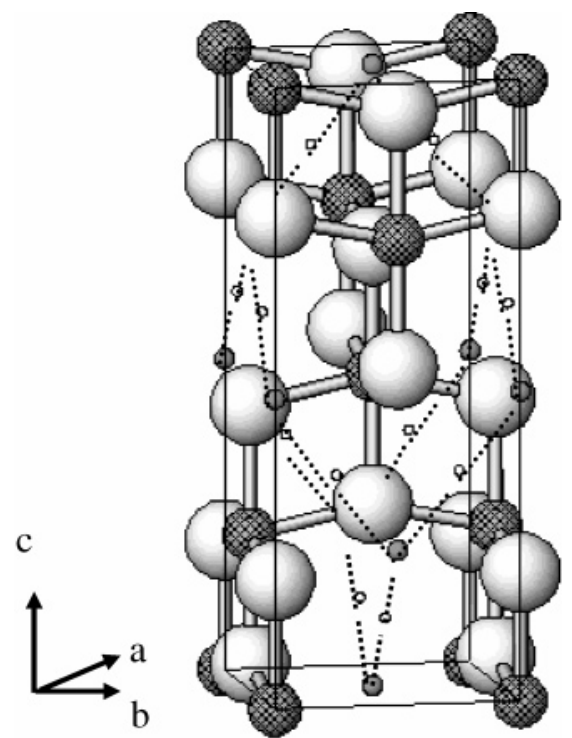

Figure 1. Anatase unit cell. Titanium ions are shown as hashed spheres, oxygen ions as large light gray spheres, and lithium ions as small gray spheres. The lithium ion migration path between octahedral sites (indicated by dotted lines) passes through a saddle point (small open circle).

TABLE 4: Calculated Energies of Schottky and Frenkel Defect Reactions for Anatase

\begin{tabular}{lcc}
\hline process & \multicolumn{1}{c}{ defect equation } & energy $(\mathrm{eV})$ \\
\hline Schottky & $\mathrm{Ti}_{\mathrm{Ti}}+2 \mathrm{O}_{\mathrm{O}} \rightarrow \mathrm{V}_{\mathrm{Ti}^{\prime \prime \prime \prime \prime}}+2 \mathrm{~V}_{\mathrm{O}}{ }^{\prime \prime}+\mathrm{TiO}_{2}$ & 19.7 \\
Frenkel & $\mathrm{Ti}_{\mathrm{Ti}} \rightarrow \mathrm{V}_{\mathrm{Ti}^{\prime \prime \prime \prime \prime}}+\mathrm{Ti}_{\mathrm{i}}{ }^{\circ} \cdots$ & 19.5
\end{tabular}

TABLE 5: Calculated Energies of Reduction and Oxidation for Anatase

\begin{tabular}{ccc}
\hline process & defect equation & \\
\hline reduction 1 & $\mathrm{Ti}_{\mathrm{Ti}}+2 \mathrm{O}_{\mathrm{O}} \rightarrow \mathrm{Ti}_{\mathrm{i}} \cdots \cdots+4 \mathrm{e}^{\prime}+\mathrm{O}_{2(\mathrm{~g})}$ & energy $(\mathrm{eV})$ \\
reduction 2 & $2 \mathrm{O}_{\mathrm{O}} \rightarrow 2 \mathrm{~V}_{\mathrm{O}}+\mathrm{O}_{2(\mathrm{~g})}+4 \mathrm{e}^{\prime}$ & 11.3 \\
oxidation 1 & $1 / 2 \mathrm{O}_{2(\mathrm{~g})} \rightarrow \mathrm{O}_{\mathrm{i}}^{\prime \prime}+2 \mathrm{~h}^{\bullet}$ & 17.9 \\
${ }^{a}$ Hole term $\left(\mathrm{h}^{\bullet}\right)=10.45 \mathrm{eV}$ and electron term $\left(\mathrm{e}^{\prime}\right)=-3.90 \mathrm{eV}$.
\end{tabular}

always relax to symmetrically equivalent octahedral sites in the anatase cell, as illustrated in Figure 1.

The energies of the isolated point defects in Table 3 were used to calculate the energies of intrinsic Schottky and Frenkel defect mechanisms as well as reduction and oxidation processes in anatase. The Schottky and Frenkel reactions, given in Table 4, are both energetically unfavorable.

Reaction energies for three redox reactions were calculated and are shown in Table 5. The energies required to add an electron or a hole to $\mathrm{Ti}^{4+}$ and $\mathrm{O}^{2-}$, respectively, were also calculated. As in previous work on transition metal oxides, ${ }^{23,24}$ these charge states were treated as small polaron species. The most energetically favorable reaction is the reduction reaction involving interstitial $\mathrm{Ti}^{4+}$, the release of $\mathrm{O}_{2}$, and the formation of electrons (in the form of $\mathrm{Ti}^{3+}$ ). The calculated value of 11.3 $\mathrm{eV}$ is in accord with experimentally determined reduction energies of Knauth and Tuller $\left(9.6 \pm 0.8 \mathrm{eV}^{48}\right)$, Baumard et al. $\left(10.6 \mathrm{eV}^{49}\right)$, and Blumenthal $\left(10.67 \mathrm{eV}^{50}\right)$. The magnitudes of the values suggest that the concentration of such defects will not be high. Therefore, $\mathrm{TiO}_{2}$ may not be readily characterized as either a Frenkel or a Schottky material because it undergoes reduction more readily than either of those reactions. This conclusion is in broad agreement with the results of Knauth and Tuller, ${ }^{48}$ who explained the ionic conductivity behavior of nanocrystalline anatase in terms of a mechanism involving both Frenkel and Ti reduction reactions. In contrast, rutile is usually 
TABLE 6: Calculated Energies of Defect Clusters Containing $\mathrm{Ti}$ Interstitials $\left(\mathrm{Ti}_{\mathrm{i}}{ }^{\cdots \cdots}\right)$ and $\mathrm{Ti}^{3+}$ Electronic Species $\left(\mathbf{T i}_{\mathbf{T i}}{ }^{\prime}\right)$

\begin{tabular}{cclc}
\hline cluster & species & \multicolumn{1}{c}{ position } & $\begin{array}{c}\text { binding } \\
\text { energy }(\mathrm{eV})\end{array}$ \\
\hline $\mathrm{Ti}_{\mathrm{i}}{ }^{\circ \cdots *} \mathrm{Ti}_{\mathrm{Ti}}{ }^{\prime}$ & $\mathrm{Ti}^{4+}$ & interstitial $(0.5,0.0,0.25)$ & -2.00 \\
& $\mathrm{Ti}^{3+}$ & lattice $(1.0,0.5,0.25)$ & \\
$\mathrm{Ti}_{\mathrm{i}}{ }^{\cdots \cdots}{ }^{\prime \cdots} 2 \mathrm{Ti}_{\mathrm{Ti}}{ }^{\prime}$ & $\mathrm{Ti}^{4+}$ & interstitial $(0.5,0.0,0.25)$ & -3.18 \\
& $\mathrm{Ti}^{3+}$ & lattice $(1.0,0.5,0.25)$ & \\
& $\mathrm{Ti}^{3+}$ & lattice $(1.0,0.0,0.0)$ & \\
$\mathrm{Ti}_{\mathrm{Ti}}{ }^{\prime} \mathrm{Ti}_{\mathrm{Ti}}{ }^{\prime}$ & $\mathrm{Ti}^{3+}$ & lattice $(1.0,0.0,0.0)$ & 0.49 \\
& $\mathrm{Ti}^{3+}$ & lattice $(0.0,0.0,0.0)$ &
\end{tabular}

TABLE 7: Calculated Energies of Defect Clusters Containing $\mathrm{Li}^{+}$and $\mathrm{Ti}^{3+}$ Defects

\begin{tabular}{lllc}
\hline \multicolumn{1}{c}{ cluster } & species & \multicolumn{1}{c}{ position } & $\begin{array}{c}\text { binding } \\
\text { energy }(\mathrm{eV})\end{array}$ \\
\hline $\mathrm{Li}_{\mathrm{i}}{ }^{\circ} \mathrm{Ti}_{\mathrm{Ti}}{ }^{\prime}$ & $\mathrm{Li}^{+}$ & interstitial $(0.5,0.0,0.25)$ & -0.54 \\
$\mathrm{Li}_{\mathrm{i}}{ }^{\circ} \mathrm{Ti}_{\mathrm{i}}{ }^{\circ \cdots \cdot} 2 \mathrm{Ti}_{\mathrm{Ti}} \mathrm{Ti}^{3+}$ & $\mathrm{Li}^{+}$ & lattice $(1.0,0.5,0.25)$ & \\
& $\mathrm{Ti}^{3+}$ & interstitial $(0.0,0.0,0.5)$ & 0.65 \\
& $\mathrm{Ti}^{3+}$ & lattice $(1.0,0.0,0.0)$ & \\
& $\mathrm{Ti}^{3+}$ & lattice $(0.0,0.0,0.0)$ & \\
$\mathrm{Li}_{\mathrm{i}}{ }^{\circ} \mathrm{Li}_{\mathrm{i}}{ }^{*}$ & $\mathrm{Li}^{+}$ & interstitial $(0.0,0.0,0.5)$ & 0.38 \\
& $\mathrm{Li}^{+}$ & interstitial $(0.5,-0.5,0.0)$ &
\end{tabular}

characterized in terms of either a Frenkel or a Schottky reaction, although there is controversy over the dominant defect reaction. ${ }^{50-55}$

Defect Clusters. It is well-known that interactions between charged defects can lead to defect clustering or trapping in metal oxides. We first considered several defect clusters consisting of $\mathrm{Ti}^{3+}$ species, which are given in Table 6 along with their calculated binding energies. The binding energy of a defect cluster, $E_{\text {binding }}$, was defined as the difference between the energy of the clustered group $\left(E_{\text {cluster }}\right)$ and the energy of the isolated defects $\left(E_{\text {individual defect }}\right)$

$$
E_{\text {binding }}=E_{\text {cluster }}-\Sigma E_{\text {individual defect }}
$$

A negative value of $E_{\text {binding }}$ indicates that the formation of the cluster is energetically favorable (i.e., the defect cluster is bound). It is interesting to note that the binding energy for the $\left[\mathrm{Ti}_{\mathrm{Ti}^{\prime}}-\mathrm{Ti}_{\mathrm{i}}{ }^{\cdots \cdots \bullet}\right.$ defect cluster is quite strong $(\sim 1 \mathrm{eV}$ per defect). This suggests there is an energetic preference for the distribution of localized electronic $\mathrm{Ti}^{3+}$ species among $\mathrm{Ti}^{4+}$ interstitials. In contrast, clusters of $\mathrm{Ti}^{3+}$ sites are unfavorable without charge compensation by $\mathrm{Ti}^{4+}$ interstitials or $\mathrm{Li}^{+}$interstitials, as discussed next.

Defect clusters consisting of $\mathrm{Li}$ interstitials $\left(\mathrm{Li}_{\mathrm{i}}{ }^{\circ}\right)$ and $\mathrm{Ti}^{3+}$ electronic species were also studied, and the resulting binding energies are given in Table 7 . The binding energy for the $\left[\mathrm{Li}_{i}{ }^{\circ}-\right.$ $\left.\mathrm{Ti}_{\mathrm{Ti}}{ }^{\prime}\right]$ neutral pair is calculated to be $-0.5 \mathrm{eV}$, which indicates that it is energetically favorable for $\mathrm{a} \mathrm{Li}^{+}$interstitial to bind to $\mathrm{a} \mathrm{Ti}^{3+}$ ion. Furthermore, the negative binding energy for a cluster containing $\mathrm{Li}^{+}$interstitial and two $\mathrm{Ti}^{3+}$ lattice defects suggests that $\mathrm{Li}^{+}$interstitials promote $\mathrm{Ti}^{3+}$ clustering. This is consistent with a wide range of experimental studies that indicate electrons become trapped at titanium sites, reducing $\mathrm{Ti}^{4+}$ to $\mathrm{Ti}^{3+}$, during lithium intercalation. Södergren et al. ${ }^{20}$ used XPS measurements to show that as $\mathrm{Li}^{+}$intercalates, $\mathrm{Ti}^{3+}$ species are created, suggesting that electrons become trapped in localized states that reduce $\mathrm{Ti}^{4+}$ to $\mathrm{Ti}^{3+}$. Wagemaker et al. ${ }^{56}$ used X-ray absorption to show that $\mathrm{Li}$ intercalation results in the occupation of the crystal-field split $\mathrm{Ti} 3 \mathrm{~d} \mathrm{t}(2 \mathrm{~g})$ orbitals. From time dependent measurements of the optical absorption and fluorescence of nanocrystalline $\mathrm{TiO}_{2}$ films under cathodic bias in $\mathrm{LiClO}_{4}$
TABLE 8: Calculated Activation Energy for Lithium Migration, as a Function of $\mathrm{Li}$ Content in $\mathrm{Li}_{x} \mathrm{TiO}_{2}$

\begin{tabular}{cc}
\hline$x$ & activation energy $(\mathrm{eV})$ \\
\hline 0.03 & 0.65 \\
0.06 & 0.57 \\
0.1 & 0.45
\end{tabular}

propylene carbonate, Kang et al. ${ }^{57}$ found that as $\mathrm{Li}^{+}$intercalates, electrons fill shallow traps located between 0.1 and $0.6 \mathrm{eV}$ below the conduction band, which is consistent with our calculated binding energy of $-0.5 \mathrm{eV}$. The positive binding energies for the second and third clusters in Table 7 indicate that clusters that carry a high net charge are not favorable.

We have shown that the most likely defect reaction for anatase is a reduction reaction involving the release of oxygen gas and the movement of a lattice $\mathrm{Ti}^{4+}$ to an interstitial site, resulting in the injection of four electrons into the Ti $3 \mathrm{~d}$ levels that form the conduction band. The $\mathrm{Ti}^{3+}$ sites so formed find it energetically favorable to cluster with interstitial $\mathrm{Ti}^{4+}$ or $\mathrm{Li}^{+}$ions, so acting as electron traps. In applications such as the DSSC, where electrons are injected into the conduction band of $\mathrm{TiO}_{2}$, these results suggest that electron traps will include Ti lattice sites close to $\mathrm{Ti}^{4+}$ or $\mathrm{Li}^{+}$interstitials.

$\mathbf{L i}^{+}$Migration. We studied the migration of interstitial $\mathrm{Li}^{+}$ by first locating the lowest energy interstitial sites and then studying the pathways between these sites. $\mathrm{Li}^{+}$interstitials were placed at various positions in the anatase unit cell and allowed to relax to the lowest energy locations. The most favorable locations were found to be at octahedral holes in which the lithium is surrounded by six oxygen atoms (Figure 1).

Various paths between these minimum energy sites were then explored by calculating the energies of $\mathrm{Li}^{+}$ions fixed at various points between neighboring interstitial sites. It was found that the migration path follows a zigzag route from one octahedral hole to the next, crossing a saddle point halfway between the octahedral holes, as shown in Figure 1. These results provide no evidence that $\mathrm{Li}^{+}$migration is preferentially along the $c$ axis, as in rutile, ${ }^{42}$ or as suggested by Koudriachova et al. for anatase. $.88,59$

The finding of a minimum energy octahedral site is consistent with experimental observations of Murphy et al. ${ }^{60}$ and Cava et al. ${ }^{61}$ who concluded, from neutron diffraction studies of the anatase to $\mathrm{Li}_{0.5} \mathrm{TiO}_{2}$ phase transformation, that $\mathrm{Li}^{+}$ions reside on the octahedral sites, and this finding is broadly consistent with studies that identify two distinct sites for $\mathrm{Li}^{+}$occupation near the center of distorted oxygen octahedra. ${ }^{62}{\mathrm{~A} \mathrm{zigzag} \mathrm{Li}^{+}}^{+}$ migration path was also found by Lunell et al. ${ }^{63}$ using periodic Hartree-Fock calculations.

The activation energy for $\mathrm{Li}^{+}$migration was defined as the difference between the saddle point energy and the octahedral site energy and was calculated for different values of the lithium content, $x$, in $\mathrm{Li}_{x} \mathrm{TiO}_{2}$. The results are listed in Table 8 . We recognize that our use of a mean field approach introduces uncertainties in the magnitude of the resulting activation energies. Nevertheless, our main concern has been to probe the trends for low lithium content and determine the atomic scale mechanism for $\mathrm{Li}^{+}$migration, and for such purposes, these mean field methods have been found to be valuable. ${ }^{23}$

The calculated activation energies in Table 8 are consistent with values determined experimentally from the temperature dependence of the diffusion coefficient, by Wagemaker et al. $\left(0.45 \pm 0.06 \mathrm{eV}^{64}\right)$ and Lindstrom et al. $(0.35 \mathrm{eV}$ for nanocrystalline anatase and $0.54 \mathrm{eV}$ for chemical vapor deposited anatase film ${ }^{65}$ ) and with the value calculated by Lunell et al. (0.51-0.56 eV for 0.06, $x<0.5$ [63]). Studies comparing the 
TABLE 9: Relaxed Surface Energies for Low Index Surfaces of Anatase

\begin{tabular}{cc}
\hline surface & $\gamma\left(\mathrm{J} / \mathrm{m}^{2}\right)$ \\
\hline$\{101\}$ & 1.73 \\
$\{100\}$ & 2.02 \\
$\{010\}$ & 2.02 \\
$\{111\}$ & 2.79 \\
$\{110\}$ & 2.79 \\
\end{tabular}

TABLE 10: Calculated Atomic Relaxation of the (001) Surface, Given as the Displacement of the Relaxed Surface Relative to the Unrelaxed Surface, in the Direction Normal to the (001) Surface and within the Surface Plane

\begin{tabular}{cccr}
\hline \multirow{2}{*}{$(001)$ surface } & \multicolumn{3}{c}{ displacement $(\AA)$} \\
\cline { 3 - 4 } atom $^{a}$ & {$[010]$} & {$[100]$} & $(001)$ \\
\hline O1 & 0.07 & -0.11 & 0.09 \\
O2 & 0.03 & -0.31 & -0.02 \\
Ti1 & 0.01 & 0.07 & -0.08
\end{tabular}

${ }^{a}$ Atoms are as labeled in Figure 3.

intercalation of $\mathrm{Li}^{+}$and $\mathrm{Na}^{+}$found that the diffusion barrier for both ions is $0.5 \mathrm{eV}$, even though the radius of $\mathrm{Na}^{+}$is larger, which led to the conclusion that the ability of the ion to polarize its environment is the primary factor controlling the diffusion activation energy. ${ }^{63}$ The trend toward lower activation energies with higher lithium content, seen in Table 8 , is consistent with Wagemaker' $\mathrm{s}^{66}$ argument that the activation energy for lithiated anatase $\left(\mathrm{Li}_{0.03} \mathrm{TiO}_{2}\right)$ is higher than for lithium titanate $\left(\mathrm{Li}_{0.5} \mathrm{TiO}_{2}\right)$ because the higher concentration of electrons leads to stronger electronic screening of the interaction between neighboring occupied interstitial sites.

Surface Structures and Morphology. The surface energies of several low index anatase planes were calculated using the methods outlined in Atomistic Simulation Methods. The energies
TABLE 11: Calculated Atomic Relaxation of the (101) Surface, Given as the Displacement of the Relaxed Surface Relative to the Unrelaxed Surface, in the Direction Normal to the (101) Surface and within the Surface Plane

\begin{tabular}{cccc}
\hline (101) surface & \multicolumn{3}{c}{ displacement $(\AA)$} \\
\cline { 3 - 4 } atom $^{a}$ & {$[010]$} & {$[10-1]$} & $(101)$ \\
\hline O1 & 0.04 & 0.28 & 0.23 \\
O2 & 0.08 & 0.30 & 0.48 \\
Ti1 & 0.03 & 0.08 & 0.02 \\
Ti2 & -0.06 & -0.22 & 0.21
\end{tabular}

${ }^{a}$ Atoms are as labeled in Figure 3.

of the relaxed surfaces are given in Table 9. The relaxed energy is lower than the unrelaxed energy by 54 and $24 \%$ for the (101) and (001) surfaces, respectively, which indicates the importance of modeling the surface relaxation. The crystal morphology resulting from the surface energies in Table 10 using Wulff's theorem is the truncated bipyramid shown in Figure 2a. The predominant plane expressed is (101) since it has the lowest energy and is therefore the most stable. The only other plane expressed is the (001) plane. Both of these planes are indicated in the anatase unit cell shown in Figure $2 b$. These results are in accord with experimental evidence of the crystal morphology from microscopy studies. ${ }^{67}$ Moreover, Hengerer et al. found that anatase single crystals have a truncated bipyramid habit exhibiting mainly the (101) and (001) surfaces, which they examine using secondary-electron imaging and low energy electron diffraction. ${ }^{68,69}$ In addition, our work is compatible with other computational studies of $\mathrm{TiO}_{2}$ surfaces that use either potential charge models ${ }^{70}$ or DFT methods. ${ }^{71}$

The displacements of the atoms in the (001) and (101) surface planes upon relaxation are given in Tables 10 and 11, respectively, with atom labels shown in Figure 3. The results for the relaxed (001) surface show the same trends as those found by Lazzeri et al. ${ }^{72}$ using electronic structure calculations. (a)
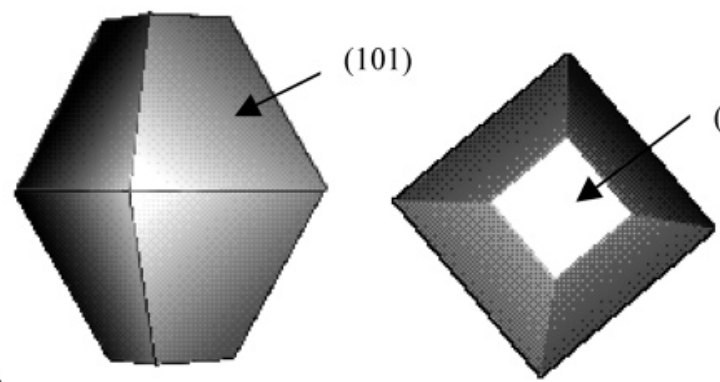

(b)

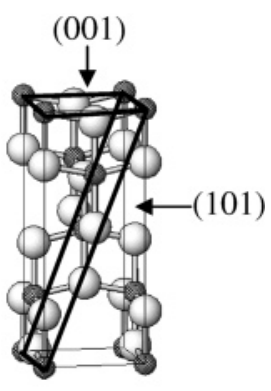

Figure 2. (a) Calculated crystal morphology showing side and top views. (b) Anatase unit cell with (001) and (101) planes indicated.

(a)

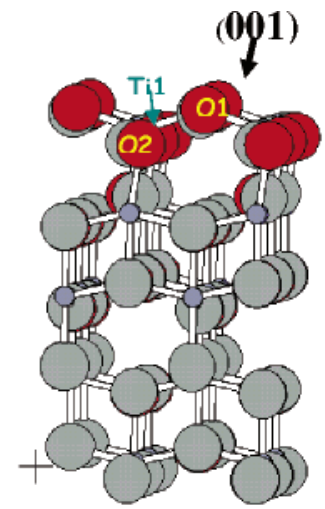

(b)

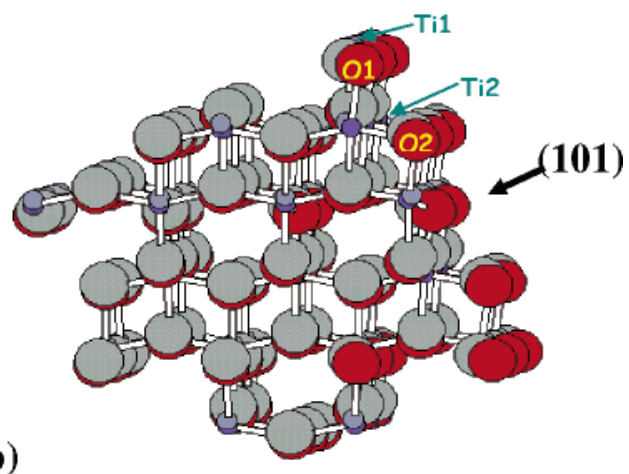

Figure 3. Relaxed anatase surfaces: (a) (001) and (b) (101). In each case, relaxed atoms (oxygen in red, titanium in blue) and unrelaxed atoms (oxygen in light gray, titanium in dark gray) are shown. The displacements of the labeled ions along the unit cell axes are given in Table 10 for (001) and Table 11 for (101). 

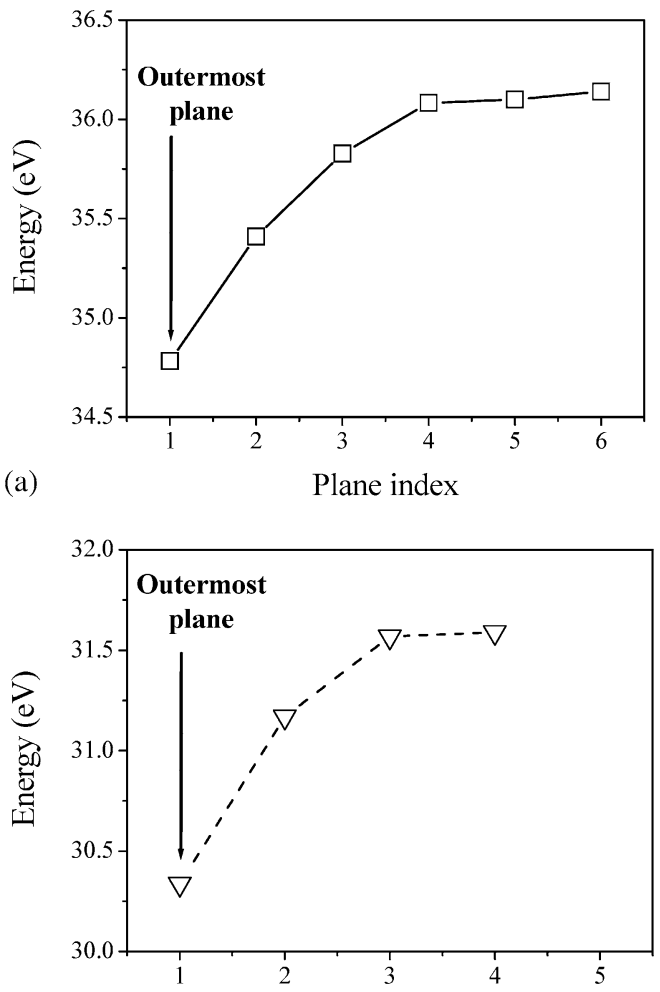

(b)

Plane index

Figure 4. Defect energy as a function of number of planes below the (101) surface of (a) $\mathrm{Ti}^{3+}$ lattice species and (b) $\mathrm{Ti}^{3+}-\mathrm{Li}^{+}$pairs.

The outermost oxygen ions (O1) push away from the surface, causing a lateral distortion in the next plane of oxygen ions (O2) and causing the Ti1 ions to shift slightly inward toward the bulk. The relaxed (101) surface has both 5- and 6-fold coordinated titanium ions (labeled Ti1 and Ti2, respectively, in Figure 3) as well as 2- and 3-fold coordinated oxygen ions (O1 and $\mathrm{O} 2$, respectively). The fully coordinated $\mathrm{Ti} 2$ and $\mathrm{O} 2$ ions have the greatest displacement from the ideal bulk positions.

Surface Defects and $\mathbf{L i}^{+}$Insertion. To study the tendency of defects to segregate toward or away from the surface, the defect energy of two major defects, an isolated $\mathrm{Ti}^{3+}$ lattice site species, and a $\mathrm{Ti}^{3+}$-interstitial $\mathrm{Li}^{+}$pair, $\left[\mathrm{Ti}_{\mathrm{Ti}^{\prime}}{ }^{\prime} \mathrm{Li}_{\mathrm{i}}{ }^{\circ}\right]$ were studied as a function of distance from the (101) surface. The (101) surface was chosen because it is the most stable anatase surface. The calculated defect energy for an isolated $\mathrm{Ti}^{3+}$ defect located in the outermost plane and in the five next-nearest planes is shown as a function of the plane index in Figure 4a. The defect energy at the outermost surface plane has the lowest value and suggests that $\mathrm{Ti}^{3+}$ defects will segregate to the surface. The calculated defect energy of a charge-neutral $\mathrm{Ti}^{3+}-\mathrm{Li}^{+}$defect cluster is shown as a function of a plane index in Figure $4 \mathrm{~b}$. Again, the lowest energy is found for the outermost plane, suggesting that defect segregation toward the surface is likely to occur.

The lattice relaxation that accompanies $\mathrm{Li}^{+}$insertion into the four outermost surface planes from the (101) surface was calculated by placing a $\mathrm{Li}^{+}$ion and $\mathrm{Ti}^{3+}$ ion in the various positions indicated in Table 12 and Figure 5. Table 12 lists the maximum displacements of neighboring lattice ions relative to the unrelaxed surface. These results show, first, that there are strong local deformations of the lattice around the lithium interstitial, such that the nearest oxygen is displaced by as much as $\sim 0.4 \AA$. Second, there is a trend suggesting that the titanium ions are displaced more when the negative end of the $\mathrm{Ti}^{3+}$ $\mathrm{Li}^{+}$dipole points outward from the surface than when it points
TABLE 12: Lattice Distortion Indicated by the Maximum Displacement of Ions as the Surface Relaxes around the $\mathrm{Li}^{+}$ Interstitials and the $\mathrm{Ti}^{3+}$ Lattice Positions Shown in Figure 5

\begin{tabular}{ccccc}
\hline & & \multicolumn{3}{c}{ maximum displacement $(\AA)$} \\
\cline { 3 - 5 } $\mathrm{Li}^{+}$position & $\mathrm{Ti}^{3+}$ position & $\mathrm{O}$ & $\mathrm{Ti}^{4+}$ & $\mathrm{Ti}^{3+}$ \\
\hline 1 & $\mathrm{~A}$ & 0.39 & 0.07 & 0.08 \\
2 & $\mathrm{~A}$ & 0.32 & 0.09 & 0.16 \\
& $\mathrm{~B}$ & 0.33 & 0.06 & 0.07 \\
3 & $\mathrm{~B}$ & 0.28 & 0.08 & 0.07 \\
& $\mathrm{C}$ & 0.27 & 0.08 & 0.07 \\
4 & $\mathrm{C}$ & 0.23 & 0.08 & 0.09
\end{tabular}

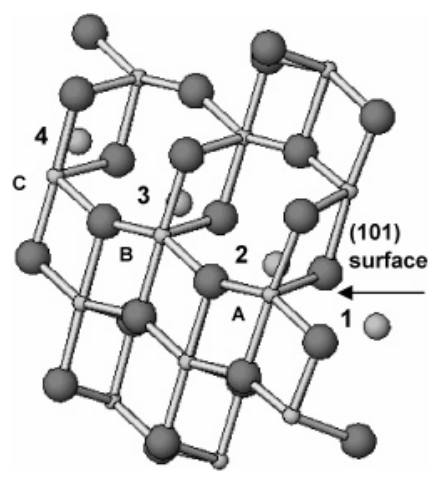

Figure 5. Schematic diagram showing $\mathrm{Li}^{+}$cations at plane index locations $(1-4)$ and $\mathrm{Ti}^{3+}$ species at positions $\mathrm{A}-\mathrm{C}$. (Maximum displacements of neighboring ions are listed in Table 12.)

inward toward the bulk. This is consistent with experimental evidence that $\mathrm{Li}^{+}$ions accumulate at the surface and form a $\mathrm{Li}^{+}$rich phase. These results suggest that the reconstruction of the anatase surfaces and the chemisorption of water at the anatase surfaces warrant further study. A study of the effect of a polar solvent environment on both defect segregation and surface structure would be of particular relevance to anatase films used in DSSCs but is beyond the scope of the present paper.

\section{Conclusions}

Computer simulation techniques have been used to investigate the defect, lithium migration, and surface properties of anatase $\mathrm{TiO}_{2}$. This atomic scale information is of relevance to the promising technological applications of anatase such as dyesensitized solar cells and lithium ion batteries. Our main conclusions are as follows:

(1) interatomic potentials were developed that reproduce the anatase crystal structure in good agreement with the observed structure (within 3\%). It was found that the intrinsic defect structure of anatase is not dominated by either Frenkel or Schottky reactions but by reduction involving the formation of $\mathrm{Ti}^{4+}$ interstitials and $\mathrm{Ti}^{3+}$ small polarons.

(2) Interactions between charged defects were investigated to probe possible defect association. $\mathrm{Ti}^{3+}-\mathrm{Li}^{+}\left[\mathrm{Ti}_{\mathrm{Ti}}{ }^{\prime}-\mathrm{Li}_{\mathrm{i}}{ }^{\circ}\right]$ defect clusters were found to be stable with a binding energy of $\sim 0.5$ $\mathrm{eV}$, which is consistent with observations of electron trapping near intercalated $\mathrm{Li}$ species.

(3) $\mathrm{The}_{\mathrm{Li}}{ }^{+}$ion is found to migrate through the bulk via a path connecting octahedral interstitial sites. The calculated activation energy for $\mathrm{Li}_{x} \mathrm{TiO}_{2}$ lies in the range of $0.45-0.65$ $\mathrm{eV}$ for $\mathrm{Li}^{+}$fractions of $x<0.10 . \mathrm{Li}^{+}$ions, through their ability to intercalate and diffuse at room temperature, are therefore expected to play an important role in the bulk system as well as the surface defect chemistry of nanocrystalline anatase electrodes. 
(4) The crystal morphology predicted from the calculated surface energies is consistent with experimental evidence, where the (101) and (001) crystal surfaces are expressed. The calculations indicate the importance of modeling the relaxation of the (001) and (101) surfaces. Isolated $\mathrm{Ti}^{3+}$ defects $\left(\mathrm{Ti}_{\mathrm{Ti}}{ }^{\prime}\right)$ and $\mathrm{Ti}^{3+}-$ $\mathrm{Li}^{+}$pairs $\left[\mathrm{Ti}_{\mathrm{Ti}}{ }^{\prime}-\mathrm{Li}_{i}{ }^{\circ}\right]$ are both predicted to segregate toward the (101) surface. This is consistent with the proposal that electron trap states are located preferentially at the anatase surface and that the lithium rich phase of $\mathrm{Li}_{x} \mathrm{TiO}_{2}$ accumulates near anatase surfaces.

With regard to the function of dye-sensitized solar cells, this work suggests that the most likely causes of electron trapping at $\mathrm{Ti}$ sites involve interstitial $\mathrm{Ti}^{4+}$ defects $\left[\mathrm{Ti}_{\mathrm{i}}{ }^{\cdots \cdots \bullet}\right.$ ] produced by reduction of $\mathrm{TiO}_{2}$, and interstitial $\mathrm{Li}^{+}$ions $\left[\mathrm{Li}_{i}{ }^{\circ}\right]$, and that these trap states are stabilized near the oxide surface. Our findings support recent experimental studies ${ }^{10}$ that demonstrate that electron trap states in nanocrystalline $\mathrm{TiO}_{2}$ electrodes are located primarily at the nanoparticle surfaces.

Acknowledgment. Thanks to Mark Read, Andrew Davies, and Craig Fisher for their assistance. C.L.O. is grateful to the Greenpeace Environmental Trust for a Ph.D. studentship.

\section{References and Notes}

(1) Fahmi, A.; Minot, C.; Silvi, B.; Causa, M. Phys. Rev. B 1993, 47

(2) Naicker, P. K.; Cummings, P. T.; Zhang, H. Z.; Banfield, J. F. J. Phys. Chem. B 2005, 109, 15243 .

(3) O’Regan, B.; Grätzel, M. Nature 1991, 353, 737.

(4) Mills, A.; Elliott, N.; Hill, G.; Fallis, D.; Durrant, J. R.; Willis, R. L. Photochem. Photobiol. Sci. 2003, 2, 591.

(5) Stashans, A.; Lunell, S.; Bergstrom, R.; Hagfeldt, A.; Lindquist, S. E. Phys. Rev. B 1996, 53, 159.

(6) Kopidakis, N.; Benkstein, K. D.; van de Lagemaat, J.; Frank, A. J. J. Phys. Chem. B 2003, 107, 11307.

(7) Nelson, J.; Haque, S. A.; Klug, D. R.; Durrant, J. R. Phys. Rev. B 2001, 63, 205321.

(8) Nelson, J.; Chandler, R. E. Coord. Chem. Rev. 2004, 248, 1181. 3019 .

(9) Gregg, B. A.; Chen, S. G.; Ferrere, S. J. Phys. Chem. B 2003, 107,

(10) Kopidakis, N.; Neale, N. R.; Zhu, K.; van de Lagemaat, J.; Frank, A. J. Appl. Phys. Lett. 2005, 87, 202106.

(11) Adachi, M.; Murata, Y.; Takao, J.; Jiu, J. T.; Sakamoto, M.; Wang,

F. M. J. Am. Chem. Soc. 2004, 126, 14943.

(12) Bisquert, J.; Vikhrenko, V. S. J. Phys. Chem. B 2004, 108, 2313.

(13) Tachibana, Y.; Haque, S. A.; Mercer, I. P.; Klug, D. R.; Durrant,

J. R. J. Phys. Chem. B 2000, 104, 1198.

(14) Tachibana, Y.; Haque, S. A.; Mercer, I. P.; Moser, J.; Klug, D. R.; Durrant, J. R. J. Phys. Chem. B 2001, 105, 7424.

(15) Kelly, C. A.; Farzad, F.; Thompson, D. W.; Stipkala, J. M.; Meyer, G. J. Langmuir 1999, 15, 7047.

(16) Haque, S. A.; Tachibana, Y.; Klug, D. R.; Durrant, J. R. J. Phys. Chem. B 1998, 102, 1745.

(17) Nakade, S.; Kambe, S.; Kitamura, T.; Wada, Y.; Yanagida, S. J. Phys. Chem. B 2001, 105, 9150.

(18) Olson, C. L. et al., to be published.

(19) Van de Krol, R.; Goossens, A.; Schoonman, J. J. Phys. Chem. B $1999,103,7151$.

(20) Södergren, S.; Siegbahn, H.; Rensmo, H.; Lindstrom, H.; Hagfeldt, A.; Lindquist, S.-E. J. Phys. Chem. B 1997, 101, 3087.

(21) Oliver, P. M.; Watson, G. W.; Kelsey, E. T.; Parker, S. C. J. Mater. Chem. 1997, 7, 563.

(22) Ammundsen, B.; Burns, G. R.; Islam, M. S.; Kanoh, H.; Roziere, J. J. Phys. Chem. B 1999, 103, 5175 .

(23) Ammundsen, B.; Roziere, J.; Islam, M. S. J. Phys. Chem. B 1997, 101,8156 .

(24) Islam, M. S.; Driscoll, D. J.; Fisher, C. A. J.; Slater, P. R. Chem. Mater. 2005, 17, 5085.

(25) Slater, B.; Catlow, C. R. A.; Gay, D. H.; Williams, D. E.; Dusastre, V. J. Phys. Chem. B 1999, 103, 10644.

(26) Balducci, G.; Kaspar, J.; Fornasiero, P.; Graziani, M.; Islam, M. S. J. Phys. Chem. B 1998, 102, 557.

(27) Catlow, C. R. A. Solid State Chemistry: Techniques; Cheetham, A. K., Day, P., Eds.; Clarendon Press: Oxford, 1987.
(28) Gale, J. D. J. Chem. Soc., Faraday Trans. 1997, 93, 629

(29) Catlow, C. R. A. J. Chem. Soc., Faraday Trans. 1989, 85, 335.

(30) Read, M. S. D.; Islam, M. S.; Watson, G. W.; Hancock, F. E. J. Mater. Chem. 2001, 11, 2597.

(31) Watson, G. W.; Kelsey, E. T.; deLeeuw, N. H.; Harris, D. J.; Parker, S. C. J. Chem. Soc., Faraday Trans. 1996, 92, 433.

(32) Wulff, G. Z. Kristallogr. Kristallgeom. 1901, 39, 449.

(33) Read, M. S. D. Ph.D. Thesis, Department of Chemistry, University of Surrey, 2001.

(34) Mackrodt, W. C.; Davey, R. J.; Black, S. N.; Docherty, R. J. Cryst. Growth 1987, 441.

(35) Parker, S. C.; Oliver, P. M.; DeLeeuw, N. H.; Titiloye, J. O.; Watson, G. W. Phase Transitions 1997, 61, 83.

(36) Sayle, D. C.; Catlow, C. R. A.; Gale, J. D.; Perrin, M. A.; Nortier, P. J. Phys. Chem. A 1997, 101, 3331.

(37) Read, M. S. D.; Islam, M. S.; Watson, G. W.; King, F.; Hancock,

F. E. J. Mater. Chem. 2000, 10, 2298.

(38) Dittrich, T.; Weidmann, J.; Koch, F.; Uhlendorf, I.; Lauermann, I. Appl. Phys. Lett. 1999, 75, 3980.

(39) Gilmer, D. C.; Colombo, D. G.; Taylor, C. J.; Roberts, J.; Haugstad, G.; Campbell, S. A.; Kim, H.-S.; Willk, G. D.; Gribelyuk, M. A.; Gladfelter W. L. Chem. Vapor Deposition 1998, 4, 9 .

(40) Kim, E. K.; Son, M. H.; Min, S.-K.; Han, Y. K.; Wang, C. H.; Yom, S. S. J. Appl. Phys. 1996, 79, 8.

(41) Gonzalez, R. J.; Zallen, R. Phys. Rev. B 1997, 55, 7014.

(42) Finklea, H. O. Semiconductor Electrodes. Studies in Physical and Theoretical Chemistry; Finklea, H. O., Ed.; Elsevier: Amsterdam, 1988; Vol. 55, p 43.

(43) le Roux, H.; Glasser, L. J. Mater. Chem. 1997, 7, 843.

(44) Grimes, R. W. J. Am. Ceram. Soc. 1994, 77, 378.

(45) Sayle, D. C.; Catlow, C. R. A.; Perrin, M. A.; Nortier, P. J. Phys. Chem. Solids 1995, 56, 799.

(46) Swamy, V.; Gale, J. D. Phys. Rev. B 2000, 62, 5406.

(47) Howard, C. J. Acta Crystallogr., Sect. B 1991, 47, 462.

(48) Knauth, P.; Tuller, H. L. J. Appl. Phys. 1999, 85, 897.

(49) Baumard, J. F.; Panis, D.; Ruffier, D. 1975, 12, 321.

(50) Blumenthal, R. N.; Coburn, J.; Baukus, J.; Hirthge, W. M. J. Phys. Chem. Solids 1966, 27, 643.

(51) Ikeda, J. A. S.; Chiang, Y.-M. J. Am. Ceram. Soc. 1993, 76, 2437.

(52) Ikeda, J. A. S.; Chiang, Y.-M.; Garratt-Reed, A. J.; Vander Sande,

J. B. J. Am. Ceram. Soc. 1993, 76, 2447.

(53) Balachandran, U.; Eror, N. G. J. Mater. Sci. 1988, 23, 2676.

(54) Millot, F.; Blanchin, M. G.; Tétot, R.; Marucco, J. F.; Poumellec,

B.; Picard, C.; Touzelin, B. Prog. Solid. State Chem. 1987, 17, 263.

(55) Hoshino, K.; Peterson, N. L.; Wiley, C. L. J. Phys. Chem. Solids $1985,46,12$.

(56) Wagemaker, M.; Lützenkirchen-Hecht, D.; van Well, A. A.; Frahm, R. J. Phys. Chem. B 2004, 108, 12456.

(57) Kang, T.-S.; Kim, D.; Kim, K.-J. J. Electrochem. Soc. 1998, 145, 1982.

(58) Koudriachova, M. V.; de Leeuw, S. W.; Harrison, N. M. Phys. Rev. B 2004, 69, 054106

(59) Koudriachova, M. V.; Harrison, N. M.; de Leeuw, S. W. Solid State Ionics 2004, 175, 829 .

(60) Murphy, D. W.; Cava, R. J.; Zahurak, S. M.; Santoro, A. Solid State Ionics 1983, 9-10, 413.

(61) Cava, R. J.; Murphy, D. W.; Zahurak, S. M.; Santoro, A.; Roth, R. S. J. Solid State Chem. 1984, 53, 64.

(62) Wagemaker, M.; Kearley, G. J.; van Well, A. A.; Mutka, H. Mulder, F. M. J. Am. Chem. Soc. 2003, 125, 840 .

(63) Lunell, S.; Stashans, A.; Ojamäe, L.; Lindström, H.; Hagfeldt, A. J. Am. Chem. Soc. 1997, 119, 7374.

(64) Wagemaker, M.; van de Krol, R.; Kentgens, A. P. M.; van Well, A. A.; Mulder, F. M. J. Am. Chem. Soc. 2001, 123, 11454.

(65) Lindstrom, H.; Sodergren, S.; Solbrand, A.; Rensmo, H.; Hjelm, J.; Hagfeldt, A.; Lindquist, S. E. J. Phys. Chem. B 1997, 101, 7710.

(66) Wagemaker, M.; van Well, A. A.; Kearley, G. J.; Mulder, F. M. Solid State Ionics 2004, 175, 191.

(67) Kay, A.; Gratzel, M. Sol. Energy Mater. Sol. Cells 1996, 44, 99.

(68) Hengerer, R.; Bolliger, B.; Erbudak, M.; Gratzel, M. Surf. Sci. 2000, $460,162$.

(69) Hengerer, R.; Kavan, L.; Krtil, P.; Gratzel, M. J. Electrochem. Soc. 2000, $147,1467$.

(70) Oliver, P. M.; Parker, S. C.; Mackrodt, W. C. Modell. Simul. Mater. Sci. Eng. 1993, 1, 755.

(71) Beltran, A.; Sambrano, J. R.; Calatayud, M.; Sensato, F. R.; Andres, J. Surf. Sci. 2001, 490, 116.

(72) Lazzeri, M.; Vittadini, A.; Selloni, A. Phys. Rev. B 2001, 63, 155409 . 